\title{
THEORETICAL PRINCIPLES OF STUDYING COMPLEX SENTENCE AT THE NOMINATIVE LEVEL
}

\author{
Alla Oleksiienko \\ $\mathrm{PhD}$, Associate Professor, Zaporizhzhia State Medical University, Ukraine \\ e-mail: alekseenko.alla@gmail.com4,orcid.org/0000-0002-5095-6065
}

\begin{abstract}
Summary
The article is devoted to the analysis of theories and systematization of knowledge about a complex sentence at the nominative level. Studying of views, concepts and theories of the sentence confirms the complexity and multifaceted nature. It is highlighted, that a sentence is a complex linguistic sign in which two levels interact and intersect - nominative and communicative, but the main attention is drawn tho the first one. The dialectic in the unity of form and content of a sentence is manifested in the duality of formal-grammatical aspect, which is considered as the superficial structure of the sentence and known by the linguists as "syntactics", and semantic-syntactic aspect, which is the deep structure of the sentence or "semantics". It is determined, that the nominative basis of a sentence is the source of the cognitive function of language, which acts as the matrix by means of which the sentence is transformed into a unit of speech, namely utterance.
\end{abstract}

Keywords: grammar, theory, taxis, coordination, subordination, clause.

DOI https://doi.org/10.23856/3913

\section{Introduction}

In modern syntactic studies, the phenomenon of "sentence" is considered a linguistic and speech phenomenon of material-ideal order, which allows multi-vector interpretation. Awareness of this truth contributes to the focus on the study of the sentence as a complex linguistic sign, the ternary structure of which provides for the unity of its formal, semantic and communicative aspects. And this, in turn, allows to consider it as a unit of syntactic level, which correlates with a certain structural scheme-invariant, which sets many specific statements and is characterized by meaningful, communicative and intonational completeness (Selivanova, 2010: 517).

This interpretation fully reveals the whole complex nature of the sentence, which is determined not so much by the number of its components, as its inherent variety of possible relationships between content and form. In this regard, the question arises about the (aspect) study of the sentence in the trinity of form, content and function.

The fact that in accordance with its symbolic essence the sentence appears in the trinity of structural, semantic and functional aspects, today does not cause objections (N. N. Arvat, I. R. Vykhovanets etc.), as it corresponds to the established triad "sentence - predicative unit statement". The first two of them reflect its nominative structure - the formal and semantic side of the sign, and the second - the ways and means of use in speech.

Nominative level of the sentence is constituted by two equal aspects - formal-grammatical and cognitive-semantic (Tesnière, 2000: 22). The first is considered, moreover, the superficial structure of the sentence, which with the light hand of Charles Morris (Morris, 2001) came into scientific circulation under the name "syntactics". The second level is at the same time its deep structure, or "semantics". 


\section{Formal and grammatical aspect of a sentence}

Interpretation of the formal-syntactic organization of a sentence is based on the understanding of the latter as a formal model (scheme, construction), as an elementary abstract pattern, as a minimal, typed configuration of the plan of expression. Modern linguistics holds the view that in his speech activity a person uses a certain abstract, general model of sentence structuring"analog of the original", which allows to produce an infinite number of specific statements.

The subject of syntactic research has long been limited to the formal and grammatical structure of the sentence, regardless of semantics and without taking into account its functions. Thus, syntactic studies did not go beyond purely linguistic categories, and the semantic component of the sentence did not go beyond clarifying the nature of syntactic relations and determining the specifics of secondary members.

According to T. V. Shmeleva (Shmeleva, 1994: 6), the central part of the meaning of the sentence is its dictum-modal organization, and O.O. Selivanova argues that this organization corresponds to two blocks - the objective semantic constant and the subjective variable (Selivanova, 2010: 118, 391). In this way, the structure of the dictum component of a sentence can be correlated with its predicate-argument framework, the components of which are the predicate, actants and sirconstants (adjuncts). The objective meaning of the sentence is most reflected in the concepts of sentence and valence, which, on the one hand, characterize the sentence as a sign of the situation, and on the other - act as a criterion for distinguishing between elementary and non-elementary sentences.

The nominative organization of a sentence is determined by the valence of the verb-predicate, its potential-connecting properties, based on the ability of the verb to open a certain number of positions, which must be filled with semantically predicted arguments. In general, valence is considered an interlevel category at the intersection of syntax, morphology and vocabulary.

Among the elements of the sentence, the quantitative composition and roles of which are determined by the nature of the predicate, there are obligatory and optional actants and free distributors. The first are valence-dependent members, because they are given by the semantic-grammatical specificity of the predicate. Electives can be eliminated without violating the grammar of the structure, while the absence of obligatory, on the contrary, leads to its grammaticality. Unlike valence-dependent syntaxes, free distributors are not quantitatively limited. They do not affect the subcategorization of the verb and are not included in the structural minimum of the sentence, but can be freely omitted or appear without violating its formal or semantic-syntactic structure.

Valence in modern linguistic theories often becomes the basis for formal-grammatical modeling of syntactic units. The sentence model is correlated with its structural scheme, which means an abstract pattern consisting of a minimum of components necessary to create a sentence and constructions of other sentences based on them (Shvedova, 1982: 84-85). The required minimum is correlated with the predicative center, often called the "predicative unit", which in the English grammatical tradition is called a clause.

The predicative center is formed by the subject and the predicate. In addition to the main members, the structural components of the sentence core can be the so-called secondary members due to valence. The predicative basis is the core of the structural scheme, the carrier of grammatical, semantic and communicative meanings, while unpredictable by the valence members (additions, definitions, circumstances) appear as optional or free distributors.

Reconstructing the sentence pattern on which the linguistic personality is oriented, constructing phrases of a certain type, it is necessary to get rid of all random and variable, to keep 
only essential signs of this sample (structural scheme, formula, model, pattern, invariant). You can simulate both simple and complex sentences. A model is "an artificial or mental system artificially created by a linguist, which reproduces or imitates by its behavior (usually in a simplified form) the behavior of some other ("real") device (original), with linguistic purposes" (Yartseva, 2000: 304). The model of a syntactic object is its record with the help of predetermined symbols, which fix those features (parameters) of the original that are considered theoretically significant.

The structure of the model reflects the understanding of the structure of the syntactic object in the parameters of its simplicity or complexity. A simple sentence differs from a complex one by its monopredictability. A simple sentence is one that includes a finite verb and other structurally obligatory clauses that fill open positions.

Crucial for the production of a sentence belongs to the syntactic connections, because the structural scheme "is constituted on the basis of nominative units - words and their analogues - and provides for the connection of these units with each other" (Prykhod'ko, 2002: 8). With the help of these means the reality of being is transmitted, as well as cognitively typed relations of the real world, which are perceived and verbalized by people. "Syntactic connection is necessary to express an opinion. Without it, we would not be able to convey any coherent content. Our speech would be a simple sequence of isolated images and ideas. It is the syntactic connection that makes a sentence a living organism, it is in it that its life force is contained. To construct a sentence means to breathe life into an amorphous mass of words, establishing a set of syntactic connections between them" (Ten'yer, 1988: 23; Tesnière, 2000: 519).

Based on this, scientists present the formal-grammatical structure of the sentence based on the distinction between major and minor members, the combinatorics of which gives an invariant scheme - the subject-predicate-object structure S - V - O (Buniyatova, 2003: 86). Minor members can be both mandatory and free distributors. The use of both allows us to talk about functional-semantic positions - members of the sentence, the combinatorial capabilities of which give grounds to distinguish between different structural types of sentences - one- and two-syllable, common and uncommon, complete and incomplete, simple and complex. Fig. 1 shows a system of formal-grammatical types of sentences - simple (monotaxis) and complex (polytaxis). It is clear that in this system the object of the given study is in the plane of a complex sentence.

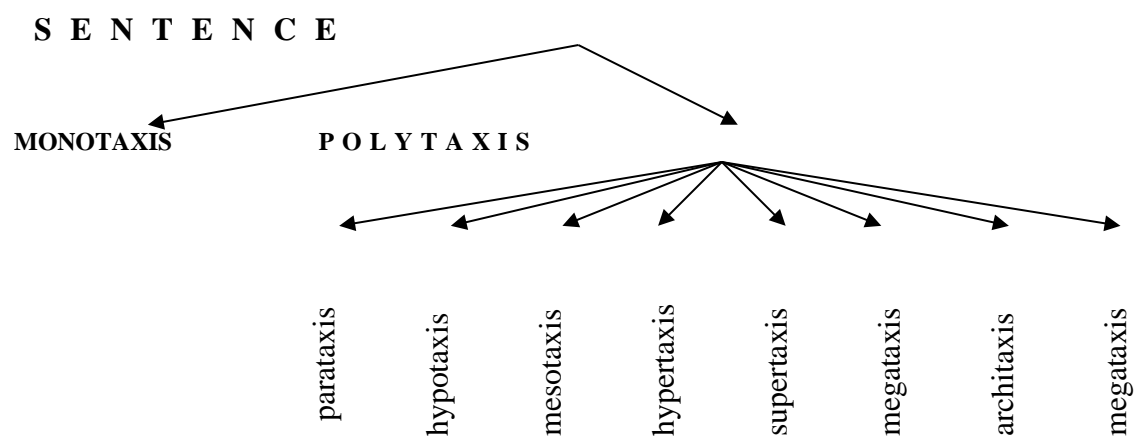

Fig. 1. System representation of a simple and complex sentence

A complex sentence (polytaxis: binomial, trine, polynomial) is traditionally understood as a combination of several simple ones, which is achieved by certain syntactic means and is 
characterized by semantic, constructive and intonational integrity. In Grammar-80 it is understood as "a holistic syntactic unit, which is a grammatical combination of sentences and functions as a message about two or more events and the relationship between them" (Shvedova, 1982: 461).

The need to distinguish between a sentence as a communicative unit and as a predicative part of a whole complex forces individual authors to abandon the term "sentence" in relation to its components. So, V. V. Vinogradov stated that "although parts of a complex sentence are homogeneous in structure with simple ones, but as a whole they do not have the semantic and intonational completeness characteristic of the sentence category, and therefore do not form separate sentences" (Vinogradov, 1960: 99).

Accordingly, a complex sentence is often understood as a unit of a special level of language - the level of a complex sentence. Like units of other levels (morphemes, tokens), it has a symbolic nature, represents the unity of the signifier and the signified. However, these aspects are much more complex than morphemes and tokens. The actual grammatical meaning of a complex sentence is the relationship it establishes between two clauses.

The invariant of a complex sentence is first of all an indicator of the relation, connection between its variables. According to its significance in the structure of a complex sentence, the marker of connection - synthetic (connective) or asyndetic (unconnected) can be compared only with the predicate of a simple sentence and qualified as a constructive top of a complex sentence. Most complex sentences can be represented by models, the constructive top of which is one or another indicator of communication. It is clear that the complete model of a complex sentence is not reduced to a conjunction: it can, and sometimes should reflect the positions of the components between which this connection is established.

If the predicative connection between its main members is decisive for monotactis, then the relations of coherence and subordination dominate in the structure of polytaxis. Conjunctive and subordinate clauses apply to almost all formal-grammatical types of complex synthetic and a small part of asyndetic sentences. Syndetic means are relatives - conjunctions and conjunction words that combine parts of para- and hypotaxis.

The basis of subordinate (hierarchical) relations is the perception and reflection of man "the idea of subordination of some phenomena to others, establishing the primacy of one of them and the secondary of another, i.e. different types of semantic dependence of language units in the space-time continuum" (Prykhod'ko, 2002: 8). In this regard, the role of the main and subordinate components in the establishment and expression of predicativeness is unequal. The organizer of the predicative center is the main part of the hypotaxis, and the subordinate clause only serves it.

Subordinate conjunction involves a one-way direction of dependence. It opposes the syllabic as an indicator of the absence of any dependence and grammatical subordination. The essence of coherent (coordinative) relations reflects the awareness of the connections between the phenomena of the real world as equal and independent (Shvedova, 1982: 615). Software connected by a coherent connection are formally equal to each other.

Given these features of the formal organization of the sentence, parataxis is a complex polypredicative formation consisting of formally autonomous parts (conjuncts), the predicative centers of which are connected by conjunctive relatives (connectors). Hypotaxis also has a polypredicative organization, but is formed by a combination of hierarchically dependent parts (subunits), one of which is the main (subordinating) and the other - the dependent (subordinated). Ukrainian grammatists have not developed a hyperonymic term for the concepts of "conjunct" and "subjunct", so the term "clause" can be quite acceptable for bringing both under a common pronoun - that predicative unit, which they, in fact, are. A clause is "any group whose 
vertex is a verb, and in the absence of a full verb - a conjunction or a grammatical element that plays the role of a conjunction. The term "clause" corresponds exactly to the English clause; the same concept ... also called an elementary sentence or predication" (Testelets, 2001: 256). Being convenient and compact, the term "clause" has recently become actively used in Ukrainian grammar studios.

A complex sentence is open to various variable transformations. This openness is based on the hierarchy of its structure, in which one unit is subordinate to another (subordination) or, conversely, is part of the subordinate system of a higher order (superordination). This can be illustrated as a superordinate scale "parataxis / hypotaxis $\rightarrow$ mesotaxis $\rightarrow$ hypertaxis $\rightarrow$ supertaxis $\rightarrow$ megataxis" (predicative units increase from left to right) or a subordinate scale "megataxis $\leftarrow$ supertaxis $\leftarrow$ hypertaxis $\leftarrow$ mesotaxis $\leftarrow$ hypotaxis / paxataxis" (decreasing from right to left).

Extrapolating the method of A. M. Prikhodko (Prykhod'ko, 2008: 219-220) to clarify the hierarchical organization of a complex sentence, O.A. Limarenko considers it a kind of sinusoidal circuit, in which each neighboring pair forms its own autonomous subsystem on the principle of "matrix - constituent" (Lymarenko, 2010: 145). However, the complicating possibilities of monotaxis are not limited to this, because the sinusoidal series can be extended both retrospectively (collotaxis, parentaxis) and prospectively (macro-, ultra-, archi-, megataxis), as, for example, suggests G.M. Hashimov (Khashimov, 1991: 33).

At the nominative level, sentence constructions are a structural-grammatical form of representation of fragments of objective reality. It is no coincidence that the English syntactic tradition distinguishes between sentence-sentence and sentence-clause, where the former appears as an independent communicative unit, and the latter - as a predicative unit that is part of the sentence, but does not correspond to it. The sentence model does not express a specific individual meaning, not a specific idea, but its specific type, which is the basis of syntactic semantics.

\section{Semantic-syntactic aspect of a complex sentence}

This aspect reflects the second member of the triad "sentence - predicative unit - statement", in which the focus is shifted to the predicate beginning of the sentence and becomes a projection of its components and relationships on the predicate-argument framework. Such a projection is directly related to semasiology - the reference aspect of the meaning of software. The corresponding section of semasiology is called semantic syntax.

Axiomatic in this regard is the postulate that sentences are complex signs - the names of situations. The situation is understood as a denotation of a syntactic unit, as its extralingual referent, as a lexical reflection of some "piece" of reality, cut out and processed by thought (Susov, 2006: 9). In the same broad sense, they speak of events, facts, states of affairs as areas of objective reality, described in a separate statement.

The inventory of denotative situations is usually described in the categories of semantic structure, which is "an abstract linguistic meaning of a sentence, a way of representing reality in thinking" (Vykhovanets, 1993: 116), which is formed by the interaction of grammatical and lexical meanings (Shvedova, 1982: 124). In other words, the semantic structure of a sentence is its abstract model, built of semantic units connected by predicate-argument relations, which reflect the objective-semantic beginnings of the sentence.

The study of the objective-semantic content of a sentence is connected with the distinction of three levels of its semantic representation - denotative, proper-semantic and logical-semantic.

Representatives of the denotative concept (for example, I. R. Vykhovanets) start from the idea of the relationship of the sentence with the situation. This relationship is studied in two 
perspectives: a) how the sentence names / outlines the situation, b) how the functions of the members of the sentence reproduce the roles performed by the objects they denote in the displayed situation. This gives reason to consider the sentence a complex sign - the name of the situation.

The study of the content of the sentence in this perspective is based on the structure of thought and the logic of predicates. Proponents of the linguistic-syntactic approach pay attention to the actual language material, study the interaction of grammatical and lexical semantics in two directions - from content to form (onomasiological) and from form to content (semasiological). In the first case it is a question of a variety of the forms expressing a certain value, in the second - about a variety of the values expressed by a certain form. This is based on various logical operations, according to which N. D. Arutyunova distinguishes such classes of logical-syntactic relations as existence, nomination, identification and characterization (Arutyunova, 2005: 2-5).

The quantitative composition of denotative situations is not fully determined. It is reduced to invariant types that are directly related to the proper semantic structure of the sentence, which means organized on a predicative basis semantic complex, which is the result of the interaction of semantic components and reflects the relationship of typed elements of reality. Usually constitutive here is a sentence - a sentence at the preverbal level with irrelevant communicative characteristics, a model of the extralingual situation, the objective meaning of the sentence, "the result of abstraction from a variety of periphrastic forms" (Vendler, 1986: 273). In this way, it appears as a "sentence devoid of grammatical originality of formal organization" (Vykhovanets, 1993: 121), as a "stable semantic core with an amodal essence" (Pankrats, 1992: 10).

Representing one extralingual situation, the sentence models its internal logical structure in the form of a combination of predicate and non-predicate (argument). As a predicate sign can be a word of any part of speech that expresses a sign, and non-predicate - a word that denotes a substance. In this case, the sentence in its most generalized form can be written as PROP $=\mathrm{P}+$ An (where $\mathrm{P}$ is a predicate, $\mathrm{A}$ is an argument, and $-\mathrm{n} \geq 1$ (Prykhod'ko, 2002: 43). For example, the situation "The dog is barking" with a monovalent predicate can be depicted as a sentence $\mathrm{P}+\mathrm{A}_{1}$; the situation described by the sentence "Max is reading the book" with a divalent predicate - as $\mathrm{P}+\mathrm{A}_{1}+\mathrm{A}_{2}$; and the situation "The child gives the father a book" with a triple "give" as $\mathrm{P}+\mathrm{A}_{1}+\mathrm{A}_{2}+\mathrm{A}_{3}$. Such arguments are considered nuclear, non-peripheral.

The idea that the predicate is the central and organizing link of the proposition has become almost axiomatic in linguistics. At first glance, the predicate has a special functional status, determining the number and quality of arguments, their semantic load, as well as the nature of syntactic relations between them. However, when generating an idea, things (non-predicate signs) are primary, not signs and attitudes (predicate signs), which are secondary. Therefore, perhaps, we can say the opposite: it is not the predicate that influences the formation of the sentence structure, but the quality and quantity of arguments determine the choice of predicate. But the dialectic of their relationship is somewhat more complex.

Along with the denotative and proper-semantic concepts of "content syntax", the logical-semantic concept, or pragmasemantic, has recently begun to assert itself. Speaking about the pragmasemantic specificity of the sentence, scholars believe that pragmatics and semantics should not be rigidly opposed to each other, but should be considered as a certain "functional unity", in which the first acts as "practical semantics", and the second provides her with data on the semantic structure of the world (Nikitin, 1996: 722). In other words, pragmatics cannot use what the language system does not offer, and the semantics of what does not happen in speech practice.

For a framework study of the plan of the content of a simple and especially complex sentence, the conceptual apparatus of semantics and pragmatics can be combined insofar as they will help to explain the specifics of the use of a particular sentence in speech. Therefore, 
pragmatics is understood here not in terms of the theoretical foundations of semantics, but as one that absorbs the semantic component of the language system. Merging into pragmasemantics, both of them must work together to explain what meanings can be embedded in the sign of the "determinative sentence" and how the speaker uses them in his speech activity.

In general, the logical-semantic (pragmasemantic) concept, forming a symbiosis of what Charles Morris separately called "semantics" (the relation of a sign to reality) and "pragmatics" (the relation of a sign to its user), is transitional and at the same time a very important link between the nominative and communicative levels of representation of simple and complex sentences.

\section{Conclusion}

In addition to its nominative representation, which serves as the basis of the cognitive function of language and is manifested in the unity of formal-grammatical and semantic-syntactic aspects, the sentence is a phenomenon of functional order, because it realizes another no less important form of language - communicative. The nominative basis of a sentence is the constructive basis of its semantics, and together they act as the matrix by which the sentence as a linguistic unit with its structure and predicative is transformed into a unit of speech - utterance.

\section{References}

Arutyunova N. D. (2005). Predlozheniye i yego smysl [The sentence and its meaning]. Moscow: Yeditorial URSS. [in Russian]

Arvat N. N. (2002). Syntaksys prostoho rechennya $v$ suchasniy rosiys'kiy movi [Syntax of a simple sentence in the modern Russian language]. Nizhyn: NDPU im. Hoholya. [in Russian] Buniyatova I. R. (2003). Evolyutsiya hipotaksysu v hermans'kykh movakh (IV-XIII ct.) [Evolution of hypotaxis in Germanic languages (IV - XIII centuries)]. Kyiv: Vyd. tsentr KNLU. [in Ukrainian]

Khashimov G. M. (1991). Tipologiya slozhnykh predlozheniy raznosistemnykh yazykov [Typology of complex sentences of different systems languages]. Tashkent: FAN. [in Russian]

Lymarenko O. A. (2010). Kontradyktorni vidnoshennya u skladnomu rechenni suchasnoyi anhliys'koyi movy [Contradictory relations in a complex sentence of modern English]. Odesa: ONU im. I.I. Mechnykova. [in Ukrainian]

Morris CH. U. (2001). Osnovaniya teorii znakov [Foundations of the theory of signs]. Moscow: Akademicheskiy proyekt; Yekaterinburg: Delovaya kniga. [in Russian]

Nikitin M. V. (1996). Kurs lingvisticheskoy semantiki [The course of linguistic semantics]. Saint-Petersburg: Nauchn. tsentr problem dialoga. [in Russian]

Pankrats YU. G. (1992). Propozitsional'naya forma predstavleniya znaniy [Propositional form of knowledge representation]. Moscow: RAN INION. [in Russian]

Prykhodko A. M. (2002). Skladnosuryadne rechennya $v$ suchasniy nimets'kiy movi [A complex sentence in modern German]. Zaporizhzhya: ZDU. [in Ukrainian]

Prykhod'ko A. M. (2008). Kontsepty i kontseptosystemy v kohnityvno-dyskursyvniy paradyhmi [Concepts and conceptual systems in cognitive-discursive paradigm]. Zaporizhzhya: Prem'yer. [in Ukrainian]

Selivanova O. O. (2010). Linhvistychna entsyklopediya [Linguistic encyclopedia]. Poltava: Dovkillya-K. [in Ukrainian]

Shmeleva T. V. (1994). Semanticheskiy sintaksis [Semantic syntax]. Krasnoyarsk: KrGU. [in Russian] 
Shvedova N. YU. etc. (1982). Grammatika-80: Russkaya grammatika. T. 2: Sintaksis. [Grammar-80: Russian grammar. Vol. 2: Syntax]. Moscow: Nauka. [in Russian]

Susov I. P. (2006). Lingvisticheskaya pragmatika [Linguistic pragmatics]. Moscow: VostokZapad. [in Russian]

Ten'yer L. (1988). Osnovy strukturnogo sintaksisa [Fundamentals of structural syntax]. Moscow: Progress. [in Russian]

Tesnière L. (2000). Grundzüge der strukturalen Syntax. Berlin, New York: Walter de Gruyter. [in German]

Testelets YA. G. (2001). Vvedeniye v obshchiy sintaksis [Introduction to general syntax]. Moscow: Ros. gos. gumanit. un-t. [in Russian]

Vendler Z. (1986). Prichinnyye otnosheniya [Causal relationships]. Moscow: Progress. [in Russian]

Vinogradov V. V. (1960). Grammatika russkogo yazyka. Sintaksis [Grammar of the Russian language. Syntax]. - Moscow: Russkiy yazyk. [in Russian]

Vykhovanets I. R. (1993). Hramatyka ukrayins'koyi movy. Syntaksys [The grammar of the Ukrainian language. Syntax]. Kyiv: Kyyivs'k. un-t. [in Ukrainian]

YAzykoznaniye. Bol'shoy entsiklopedicheskiy slovar' (2000). [Linguistics. Big Encyclopedic Dictionary]. Moscow: Bol'shaya Rossiyskaya entsiklopediya. [in Russian] 